\title{
PTC located in the upper pole is more prone to lateral lymph node metastasis and skip metastasis
}

\author{
Yi Dou, Daixing Hu, Yingji Chen, Wei Xiong, Qi Xiao and Xinliang Su* (D)
}

\begin{abstract}
Background: Lateral lymph node metastasis (LLNM) is very common in papillary thyroid carcinoma (PTC). The influence of tumour location on LLNM remains controversial. The purpose of this study was to reveal the association between PTC tumours located in the upper pole and LLNM.

Methods: We reviewed a total of 1773 PTC patients who underwent total thyroidectomy with central and lateral lymph node dissection between 2013 and 2018. Patients were divided into two groups according to tumour location. Univariate and multivariate analyses were performed to identify risk factors associated with LLNM and "skip metastasis".

Results: In the upper pole group, LLNM and skip metastasis were significantly likely to occur. Multivariate analysis showed that tumours located in the upper pole, male sex, extrathyroidal extension (ETE), central lymph node metastasis (CLNM) and tumour size were independent risk factors for LLNM, with odds ratios ([ORs], 95\% confidence intervals [Cls]) of 2.136 (1.707-2.672), 1.486 (1.184-1.867), 1.332 (1.031-1.72), 4.172 (3.279-5.308) and 2.496 (1.844-3.380), respectively. Skip metastasis was significantly associated with the primary tumour location in the upper pole and age $>$ 55 years, with ORs of 4.295 (2.885-6.395) and 2.354 (1.522-3.640), respectively.

Conclusions: In our opinion, papillary thyroid tumours located in the upper pole may have an exclusive drainage pathway to the lateral lymph nodes. When the tumour is located in the upper pole, lateral neck dissection should be evaluated meticulously.
\end{abstract}

Keywords: Papillary thyroid carcinoma (PTC), Lymphatic metastasis, Tumour location, Lymph node dissection

\section{Introduction}

The morbidity of thyroid carcinoma is increasing worldwide. From 2011 to 2015, 63,324 patients were diagnosed with thyroid carcinoma in America [1]. In Europe, the incidence of thyroid cancer in women was three times higher than that in men in 2012 according to data from the Cancer Registry [2]. In China, the incidence rates of thyroid carcinoma ranked third for females in 2015 [3]. Papillary thyroid carcinoma (PTC) has an excellent prognosis, with 10 -year survival rates ranging

\footnotetext{
*Correspondence: suxinliang@21cn.com

Department of Endocrine and Breast Surgery, the First Affiliated Hospital of Chongqing Medical University, Chongqing 400016, China
}

from 90 to $97 \%[4,5]$. In PTC, however, lymph node metastasis is common in the early stage and is related to an increased risk of local-regional recurrence and the reoperation rate [6, 7]. Many previous studies have reported that a tumour located in the upper pole was an independent risk factor for lymph node metastasis $[8,9]$. YK et al. [10] found that upper pole tumours had a pooled odds ratio (OR) of 2.96 (95\% confidence interval $[\mathrm{CI}]=1.93-4.53, P<0.001)$ and were significantly associated with lateral lymph node metastasis (LLNM). Moreover, skip metastasis (LLNM without central lymph node metastasis [CLNM]) was also significantly associated with the primary tumour location in the upper pole,

(c) The Author(s). 2020 Open Access This article is licensed under a Creative Commons Attribution 4.0 International License, which permits use, sharing, adaptation, distribution and reproduction in any medium or format, as long as you give appropriate credit to the original author(s) and the source, provide a link to the Creative Commons licence, and indicate if changes were made. The images or other third party material in this article are included in the article's Creative Commons licence, unless indicated otherwise in a credit line to the material. If material is not included in the article's Creative Commons licence and your intended use is not permitted by statutory regulation or exceeds the permitted use, you will need to obtain permission directly from the copyright holder. To view a copy of this licence, visit http://creativecommons.org/licenses/by/4.0/ The Creative Commons Public Domain Dedication waiver (http://creativecommons.org/publicdomain/zero/1.0/) applies to the data made available in this article, unless otherwise stated in a credit line to the data. 
as reported by several study [11]. A report by Lei et al. [12] showed that primary tumours in the upper pole had an OR of 18.495 and were associated with skip metastasis in 450 PTC patients. These studies indicate that the regular pattern of lymph node metastasis in PTC is difficult to predict due to the different tumour locations. In the present study, we aimed to reveal the association between PTC located in the upper pole and LLNM and propose an independent lymph node drainage pathway.

\section{Materials and methods}

\section{Patients}

A retrospective analysis of consecutive patients with PTC who underwent surgery at the Department of Endocrine and Breast Surgery of the First Affiliated Hospital of Chongqing Medical University between January 2013 and December 2018 was performed. The study was approved by the Medical Ethics Committee of The First Affiliated Hospital of Chongqing Medical University (2020-218). Consent has been obtained from each patient or subject after full explanation of the purpose and nature of all procedures used. Patients who met the following criteria were excluded: incomplete clinicopathologic data, other types of thyroid carcinoma, underwent a reoperation, tumour occupying the whole lobe, a bilateral tumour and an isthmus tumour and distant metastasis. Based on these criteria, 1773 patients with PTC were included.

All patients were diagnosed through fine-needle aspiration biopsy (FNAB) before surgery, and the diagnosis was confirmed by pathological biopsy as PTC. Physical examinations, ultrasonography and fibrolaryngoscopy were routinely performed on each patient. All patients underwent total thyroidectomy (TT) with central compartment lymph node dissection (LND) and ipsilateral therapeutic or prophylactic lateral neck LND, of which most were therapeutic dissection due to clinical lymph nodes positive(cN1). Prophylactic dissection was performed in few patients with risk factors for lateral lymph node metastasis (extrathyroidal extension, central lymph node metastasis, intraoperative findings and so on). The central lymph nodes and lateral lymph nodes (including levels II, III and IV) were divided into different regions and examined pathologically by three pathologists. Tumour location was categorized as upper pole, middle pole, and lower pole based on the preoperative ultrasound report from two experienced ultrasound doctors and the findings obtained during the operation. Since there is no clear anatomical division or guideline, the thyroid glands are bisected into three equal volumes (upper pole, middle pole and lower pole) according to the consensus of most medical center. Tumours occupying more than one single pole were included in the upper pole group when the upper pole was involved.

\section{Clinicopathological variables}

Tumour multifocality, Hashimoto's thyroiditis (HT) and extrathyroidal extension (ETE) were confirmed by a pathological examination. The $t$ test, the chi-squared test or Fisher's exact test was used to compare differences in demographic and pathologic data on sex (male, female), age ( $\leq 55$ years, $>55$ years), tumour size $(\leq 10 \mathrm{~mm}$, between 10 and $20 \mathrm{~mm}$ and $>20 \mathrm{~mm}$ ), tumour location (upper/middle/lower pole), HT (yes, no), multifocality (yes, no) and ETE (yes, no) between the patients with or without LLNM. Logistic regression was used for multivariate analysis to estimate the statistical significance. All variables with significant differences in the univariate analysis were included in the multivariate analysis. Statistical significance was defined as $P<0.05$, and the analyses were performed using SPSS version 25.0 (SPSS Inc., Chicago, IL, United States) and GraphPad 8.0.

\section{Results \\ Clinicopathologic characteristics}

Of the 1773 PTC patients included, 513 (28.9\%) were male, and 1260 (71.1\%) were female. The male-to-female ratio was 1:2.46. The median age of the patients was $42.1 \pm 12.4$ years. The mean size of the largest primary thyroid tumour was $1.5 \pm 1.0 \mathrm{~cm}$. Primary tumours located in the upper pole were found in $624(35.2 \%)$ patients. A total of $862(48.6 \%)$ patients had a tumour smaller than $1 \mathrm{~cm}, 624(35.2 \%)$ had a tumour between 1 and $2 \mathrm{~cm}$ and $287(16.2 \%)$ had a tumour larger than 2 $\mathrm{cm}$. Gross ETE was observed in 375 (21.2\%) patients. HT was present in 247 (13.9\%) patients, and multifocal tumours were present in $312(17.6 \%)$ patients. The analysis indicated that 1197 (67.5\%) patients had CLNM, with an average number of $2.6 \pm 3.3$ metastatic lymph nodes. A total of 825 (46.5\%) patients had LLNM, with an average number of $1.7 \pm 2.9$ metastatic lymph nodes. Among these patients, 684 (38.6\%) had level II/III LNM, and 374 (21.1\%) had level IV LNM. "Skip metastasis" was observed in 139 (7.8\%) patients (Table 1) (Fig. 1).

\section{Type of lymph node metastasis}

According to tumour location, the patients were divided into two groups. No metastatic lymph nodes were found in $160(25.6 \%)$ patients and $277(24.1 \%)$ patients in each group. A total of $384(33.4 \%)$ patients in the non-upper pole group experienced metastasis to level VI without lateral neck lymph node involvement (pathologic N1a disease, pN1a), which was more than those in the upper pole group (20.7\%). In the upper pole group, $53.68 \%$ of patients had LLNM. In contrast, $42.65 \%$ of patients in the non-upper pole group had LLNM. Skip metastasis was observed in 97 patients (15.54\%) in the upper pole group and $42(3.66 \%)$ in the non-upper pole group, with 
Table 1 Baseline clinicopathologic characteristics of 1773 PTC patients

\begin{tabular}{|c|c|c|c|}
\hline & Mean + SD & & Mean + SD \\
\hline Age (years) & $42.1 \pm 12.4$ & Number of CLNMs & $2.6 \pm 3.3$ \\
\hline Size $(\mathrm{cm})$ & $1.5 \pm 1.0$ & Number of LLNM & $1.7 \pm 2.9$ \\
\hline Sex & & CLNMs & \\
\hline Female & $1260(71.1 \%)$ & No & $576(32.5 \%)$ \\
\hline Male & $513(28.9 \%)$ & Yes & $1197(67.5 \%)$ \\
\hline Age & & LLNM & \\
\hline$<=55$ & 1289 (84.9\%) & No & $948(53.5 \%)$ \\
\hline$>55$ & $230(15.1 \%)$ & Yes & $825(46.5 \%)$ \\
\hline Size $(\mathrm{cm})$ & & Level II/II & \\
\hline$\leq 1$ & $862(48.6 \%)$ & No & $1089(61.4 \%)$ \\
\hline $1 \sim 2$ & $624(35.2 \%)$ & Yes & $684(38.6 \%)$ \\
\hline$>2$ & $287(16.2 \%)$ & Level IV & \\
\hline Location & & No & 1399 (78.9\%) \\
\hline Upper & $624(35.2 \%)$ & Yes & $374(21.1 \%)$ \\
\hline Non-upper & 1149 (64.8\%) & $\mathrm{pNx}$ & \\
\hline ETE & & pNO & $437(24.6 \%)$ \\
\hline No & 1398 (78.8\%) & pN1 & $1336(75.4 \%)$ \\
\hline Yes & $375(21.2 \%)$ & & \\
\hline Multifocality & & Hashimoto & \\
\hline No & 1461 (82.4\%) & No & $1526(86.1 \%)$ \\
\hline Yes & $312(17.6 \%)$ & Yes & 247 (13.9\%) \\
\hline
\end{tabular}

ETE extrathyroidal extension, CLNM central lymph node metastasis, LLNM lateral lymph node metastasis, $p N O$ pathologic node-negative, $p N 1$ pathologic node-positive

a statistically significant difference $(P<0.05)$ (Table 2 and Fig. 2).

\section{Clinicopathological variables associated with LLNM}

Clinicopathological differences between LLNM and clinicopathological variables are shown in Table 3. A total of 825 patients $(46.5 \%)$ had LLNM. Univariate analysis (Table 3) indicated that this condition was significantly associated with sex $(P<0.001)$, tumour size $(P<0.001)$, tumour location $(P<0.001)$, ETE $(P<0.001)$ and CLNM $(P<0.001)$. Multivariate analysis (Table 3$)$ revealed that male sex (adjusted OR (95\% CI) 1.486 (1.184-1.867)), tumour location in the upper pole (2.136 (1.707-2.672)), large tumour size (2.496 (1.844-3.380)) and CLNM (4.172 (3.279-5.308)) remained independent significant risk factors (all $P<0.05$ ).

\section{Clinicopathological variables associated with skip metastasis and LLNM}

Table 4 shows that the skip metastasis rate was higher in older patients $(P<0.001)$ and in tumours located in the upper pole $(P<0.001)$. In the multivariate analysis, these factors remained independently associated with skip metastasis; the adjusted ORs with 95\% CIs were 2.354 $(1.522-3.640)$ and 4.295 (2.885-6.395), respectively.

\section{Discussion}

Lymph node metastasis is very common in PTC, with an occurrence rate of $30-80 \%[13,14]$. Even in papillary thyroid microcarcinoma (PTMC), the reported lymph node metastasis rate is up to $50 \%[9,15]$. In this study, we analysed data from a total of 1773 PTC patients and found different patterns of lymph node metastasis depending on tumour location. PTC was more likely to present a sequential lymph node metastasis pattern (first to the central and then to the lateral compartments) when tumours were located in the middle or lower pole, which is in agreement with two previous studies [16, 17]. The rate of skip metastasis was also significantly low. However, when tumours were located in the upper pole, they tended to metastasize to the lateral lymph nodes more frequently. This finding indicates that upper pole tumours more likely involve the lateral compartment than tumours located at other positions, which has also been reported in several studies $[18,19]$. Another study [20] has shown that upper pole tumours seem to be at a high risk for malignancy. Jasim et al. [21] argued that upper thyroid nodules had a higher risk for malignancy, with an OR of 1.8 (1.2-2.7), followed by middle and lower thyroid nodules in a review of 3313 adult patients. However, there were no clear recommendations on whether lateral LND should be performed when the tumour is located in the upper pole [5, 22]. If tumour location was not considered, only central compartment lymphadenectomy was performed, and the potential risk of lateral lymph metastasis might have been ignored. In addition to the previously confirmed influencing factors, tumour location should be evaluated seriously. LND should be managed appropriately during surgery, even in small tumours located in the upper pole, to avoid local recurrence and distant metastasis.

Tumours located in the upper pole were identified as an independent risk factor for skip metastasis in our study. Luo et al. [23] reviewed 1031 PTMC patients and established that tumour location in the upper pole was closely correlated with lateral cervical lymph node metastasis and not CLNM. These unique phenomena are conventionally called "skip metastasis" in most studies. However, given the current retrospective study and anatomical support of lymphatic spread, this nomenclature may not be appropriate. There might be an independent lymphatic drainage pathway in the upper pole of the thyroid tumour that directly drains to the lateral region and into the deep vein without passing through the central region. In other words, the lateral lymph node might be the first lymph drainage station for an upper pole tumour. Likhterov et al. [16] also supported the 


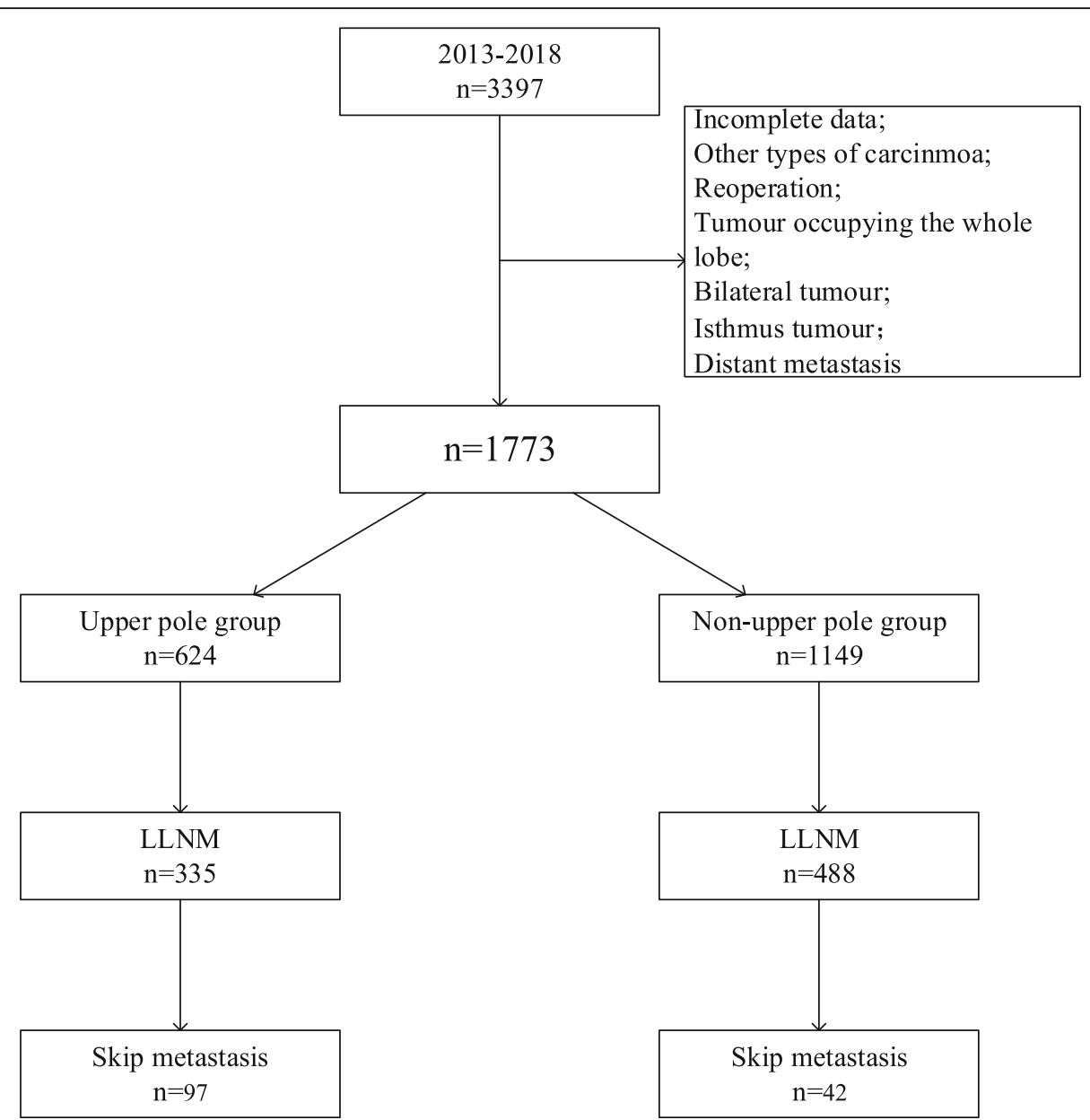

Fig. 1 Flow diagram of all patients who underwent lateral neck dissection. LLNM, lateral lymph node metastasis; skip metastasis, lateral lymph node metastasis without central lymph node metastasis

exclusive lymphatic pathway of the upper pole using lymphatic anatomic studies. Jianyong et al. [12] used carbon nanoparticles injected into the upper pole of the thyroid lobe, and $70 \%$ of tumours showed skip metastasis (black staining), in which all of the patients showed level II skip metastasis. This potential lymphatic drainage pathway may cause occult lymph node metastasis and should be carefully considered during surgical

Table 2 Lymph node metastasis type in 1773 PTC patients

\begin{tabular}{llll}
\hline & Upper pole group & Non-upper pole group & $P$ value \\
\hline$C-L-$ & $160(25.64 \%)$ & $277(24.11 \%)$ & $<0.001$ \\
$C+L-$ & $129(20.67 \%)$ & $384(33.42 \%)$ & \\
$C-L+$ & $97(15.54 \%)$ & $42(3.66 \%)$ & \\
$C+L+$ & $238(38.14 \%)$ & $446(38.82 \%)$ & \\
\hline
\end{tabular}

$C-L-$ central lymph node negative with lateral lymph node negative, $C+L-$ central lymph node positive with lateral lymph node negative, $C-L+$ central lymph node negative with lateral lymph node positive, $C+L+$ central lymph node positive with lateral lymph node positive intervention. This hypothesis needs confirmation through more prospective research and anatomical evidence.

Our study also demonstrated that male sex, a large tumour size, ETE and CLNM were significantly correlated with LLNM by multivariate analysis. A randomeffects model with 16 studies [10] showed that male patients had a poorer OR (1.72) than female patients with LLNM, which was in line with recent research [24]. Many previous studies have indicated that a large tumour size is associated with LLNM and leads to later tumour staging $[24,25]$. Kim et al. [26] reported that a tumour size $>0.5 \mathrm{~cm}$ was an independent predictor of LLNM (adjusted OR 1.295) according to a review of 5656 PTMC patients, which is consistent with our study. In the present study, ETE was associated with LLNM. Kim et al. [27] found that ETE was an admittedly important prognostic factor for LLNM. However, in patients with skip metastasis, only age and tumour location remained statistically significant, which was congruent 


\section{Different types of lymph node metastasis between the two groups

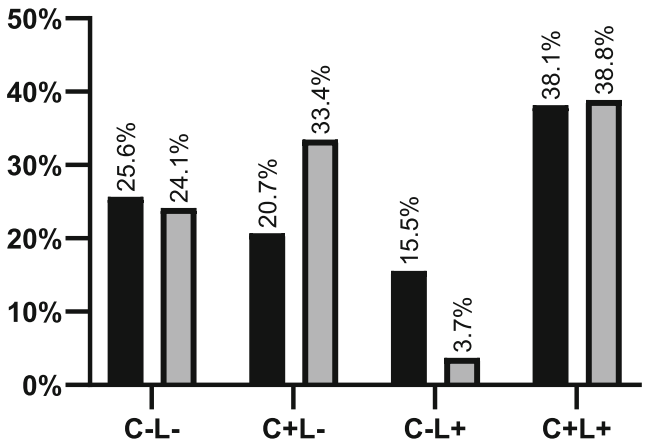 \\ Upper pole group \\ ㅁ Non-upper pole group}

Fig. 2 different type of the lymph node metastasis between the two group. $C-L-$, central lymph node negative with lateral lymph node negative; $C+L-$, central lymph node positive with lateral lymph node negative; $C-L+$, central lymph node negative with lateral lymph node positive; $C+L+$ central lymph node positive with lateral lymph node positive

with our previous study [28]. A recent meta-analysis of 13 articles [29] also found that older age and upper pole tumours were risk factors for LLNM.

The most common metastatic site of PTC is the central compartment, which has been reported to be an independent contributor to LLNM [25, 30]. This conclusion confirms the main lymph node drainage pathway of the thyroid. CLNM, which was the main contributor among all patients in our study, was observed at a lower rate in the upper pole group compared with the non-upper pole group. This result further indicates that there might be a direct lymph pathway from the upper pole of the thyroid to the lateral compartments, consistent with a previous report [31].

There is no official standard or acknowledged anatomical mark for the location of thyroid tumours. In our study, tumour location was determined with ultrasound and findings during the operation. There should be a concise standard based on imaging (US, CT, etc.) and pathology in future recommendations.

Table 3 Univariate and multivariate analyses of factors associated with lateral lymph node metastasis in 1773 PTC patients

\begin{tabular}{|c|c|c|c|c|c|}
\hline & \multicolumn{3}{|c|}{ Univariate analysis } & \multicolumn{2}{|l|}{ Multivariate analysis } \\
\hline & LLNM (-) & LLNM (+) & $P$ value & Adjusted OR (95\% Cl) & $P$ value \\
\hline & $n=948$ & $n=825$ & & & \\
\hline$\overline{\text { Sex }}$ & & & $<0.001^{*}$ & & \\
\hline Female & $713(75.2 \%)$ & $547(66.3 \%)$ & & & \\
\hline Male & $235(24.8 \%)$ & $278(33.7 \%)$ & & $1.486(1.184-1.867)$ & $<0.001^{*}$ \\
\hline Age & & & 0.536 & & \\
\hline$<=55$ & $673(85.4 \%)$ & $616(84.3 \%)$ & & & \\
\hline$>55$ & $115(14.6 \%)$ & 115 (15.7\%) & & & \\
\hline Size $(\mathrm{cm})$ & & & $<0.001^{*}$ & & \\
\hline$\leq 1$ & $549(57.9 \%)$ & $313(37.9 \%)$ & & & \\
\hline $1 \sim 2$ & $291(30.7 \%)$ & $333(40.4 \%)$ & & $1.707(1.359-2.144)$ & $<0.001^{\circ}$ \\
\hline$>2$ & $108(11.4 \%)$ & $179(21.7 \%)$ & & $2.496(1.844-3.380)$ & $<0.001^{\prime}$ \\
\hline Location & & & $<0.001$ & & \\
\hline Upper & $289(30.5 \%)$ & $335(40.6 \%)$ & & $2.136(1.707-2.672)$ & $<0.001^{*}$ \\
\hline Non-upper & $659(69.5 \%)$ & $490(59.4 \%)$ & & & \\
\hline ETE & $160(16.9 \%)$ & 215 (26.1\%) & $<0.001^{*}$ & $1.332(1.031-1.72)$ & $0.028^{*}$ \\
\hline Multifocality & $152(16.0 \%)$ & $160(19.4 \%)$ & 0.064 & & \\
\hline Hashimoto & $136(14.3 \%)$ & $111(13.5 \%)$ & 0.589 & & \\
\hline CLNM & $511(53.9 \%)$ & $686(83.2 \%)$ & $<0.001^{*}$ & $4.172(3.279-5.308)$ & $<0.001$ \\
\hline
\end{tabular}

*Symbol for $p<0.05$

ETE extrathyroidal extension, CLNM central lymph node metastasis, LLNM lateral lymph node metastasis, OR odds ratio, Cl confidence interval 
Table 4 Relationships between clinicopathological characteristics and skip metastasis

\begin{tabular}{|c|c|c|c|c|c|}
\hline & Univariate ana & & & Multivariate analysis & \\
\hline & $(-)$ & $(+)$ & $P$ value & Adjusted OR (95\% Cl) & $P$ value \\
\hline Sex & & & 0.411 & & \\
\hline Female & 1157 (70.8\%) & $103(74.1 \%)$ & & & \\
\hline Male & 477 (29.2\%) & 36 (25.9\%) & & & \\
\hline Age & & & $<0.001^{*}$ & $2.354(1.522-3.640)$ & $<0.001^{*}$ \\
\hline$<=55$ & $1200(86.0 \%)$ & 89 (72.4\%) & & & \\
\hline$>55$ & 196 (14.0\%) & $34(27.6 \%)$ & & & \\
\hline Size $(\mathrm{cm})$ & & & 0.101 & & \\
\hline$\leq 1$ & 796 (48.7\%) & $66(47.5 \%)$ & & & \\
\hline $1 \sim 2$ & $582(35.6 \%)$ & $42(30.2 \%)$ & & & \\
\hline$>2$ & $256(15.7 \%)$ & $31(22.3 \%)$ & & & \\
\hline Location & & & $<0.001^{*}$ & 4.295 (2.885-6.395) & $<0.001^{*}$ \\
\hline Upper & 527 (32.3\%) & $97(69.8 \%)$ & & & \\
\hline Non-upper & 1107 (67.7\%) & $42(30.2 \%)$ & & & \\
\hline ETE & $338(20.7 \%)$ & $37(26.6 \%)$ & 0.100 & & \\
\hline Multifocality & $283(17.3 \%)$ & 29 (20.9\%) & 0.292 & & \\
\hline Hashimoto & 229 (14.0\%) & $18(12.9 \%)$ & 0.728 & & \\
\hline
\end{tabular}

*Symbol for $p<0.05$

ETE extrathyroidal extension, $\mathrm{OR}$ odds ratio, $\mathrm{Cl}$ confidence Interval

There were several potential limitations to this study. Several clinicopathological features, such as histological subtype, Braf mutation and lymphovascular invasion, were not provided. Furthermore, we are examining more detailed pathological reports and long-term follow-up data.

\section{Conclusion}

The lymphatic drainage pathway of PTC is complex. The extent of LND in each patient should be individualized. When the tumour is located in the upper pole of the thyroid, it is more likely to have LLNM than when a tumour is not located in the upper pole. The risks and benefits of preventive lateral LND should be discussed with the patient.

\section{Abbreviations}

ETE: Extrathyroidal extension; CLNM: Central lymph node metastasis; LLNM: Lateral lymph node metastasis; pNO: Pathologic node-negative; pN1: Pathologic node-positive; PTC: Papillary thyroid carcinoma; ORs: Odds ratios; Cls: Confidence intervals; T: Total thyroidectomy; FNAB: Fine-needle aspiration biopsy; HT: Hashimoto's thyroiditis

\section{Authors' contributions}

The first author of this manuscript is Yi Dou. Yi Dou, Daixing Hu and Xinliang Su designed this research. Wei Xiong and Qi Xiao collected the data. Yi Dou, Wei Xiong and Qi Xiao performed the statistical analyses. Yingji Chen and Daixing Hu reviewed the results, interpreted the data and wrote the manuscript. Yi Dou, Yingji Chen, Daixing Hu and Xinliang Su discussed and edited the paper. All authors read and approved the final version of the paper.

\section{Funding}

This research did not receive any specific grant from any funding agency in the public, commercial or not-for-profit sector.

\section{Availability of data and materials}

The datasets used and/or analysed during the current study are available from the corresponding author on reasonable request.

Ethics approval and consent to participate

The study was approved by the Medical Ethics Committee of The First Affiliated Hospital of Chongqing Medical University (2020-218).

\section{Consent for publication}

Not applicable

\section{Competing interests}

The authors declare that they have no competing of interests.

Received: 13 May 2020 Accepted: 22 July 2020

Published online: 28 July 2020

\section{References}

1. Noone AM HN, Krapcho M, Miller D, Brest A, Yu M, Ruhl J, Tatalovich Z, Mariotto A, Lewis DR, Chen HS, Feuer EJ, Cronin KA (eds). SEER Cancer Statistics Review, 1975-2015, National Cancer Institute. Bethesda, MD, https://seer.cancer.gov/csr/1975_2015/, based on November 2017 SEER data submission, posted to the SEER web site. April 2018.

2. Pacini F, Castagna MG, Brilli L, Pentheroudakis G. Thyroid cancer: ESMO Clinical Practice Guidelines for diagnosis, treatment and follow-up. Ann Oncol. 2012;23 Suppl 7:vii110-119. doi:https://doi.org/10.1093/annonc/ mds230.

3. Zheng R-S, Sun KX, Zhang S, Zeng H, Zou X-N, Chen R, et al. Report of cancer epidemiology in China, 2015. Zhonghua Zhong Liu Za Zhi [Chinese journal of oncology]. 2019;41:19-28. doi:https://doi.org/10.3760/cma.j.issn. 0253-3766.2019.01.005

4. Lim H, Devesa SS, Sosa JA, Check D, Kitahara CM. Trends in thyroid cancer incidence and mortality in the United States, 1974-2013. Jama. 2017;317(13): 1338-48. https://doi.org/10.1001/jama.2017.2719. 
5. Haddad Rl, Nasr C, Bischoff L, Busaidy NL, Byrd D, Callender G, et al. NCCN Guidelines insights: thyroid carcinoma, Version 2.2018. J Natl Compr Cancer Netw. 2018;16(12):1429-40. https://doi.org/10.6004/jnccn.2018.0089.

6. Yuksel UM, Turanli S, Acar Y, Berberoglu U. The prognostic factors for clinical N1b patients in thyroid papillary carcinoma. J Cancer Res Ther. 2019;15(3): 681-5. https://doi.org/10.4103/jcrt.JCRT_1011_16.

7. Hasney CP, Amedee RG. What is the appropriate extent of lateral neck dissection in the treatment of metastatic well-differentiated thyroid carcinoma? Laryngoscope. 2010;120(9):1716-7. https://doi.org/10.1002/lary. 20994.

8. Gong Y, Yang J, Yan S, Su A, Liu F, Gong R, et al. Pattern of and clinicopathologic risk factors for lateral lymph node metastases in papillary thyroid carcinoma patients with lateral cervical lymphadenopathy. Medicine (Baltimore). 2018;97(36):e12263. https://doi.org/10.1097/MD. 0000000000012263

9. Back K, Kim JS, Kim JH, Choe JH. Superior located papillary thyroid microcarcinoma is a risk factor for lateral lymph node metastasis. Ann Surg Oncol. 2019;26(12):3992-4001. https://doi.org/10.1245/s10434-019-07587-2.

10. So YK, Kim MJ, Kim S, Son YI. Lateral lymph node metastasis in papillary thyroid carcinoma: a systematic review and meta-analysis for prevalence, risk factors, and location. Int J Surg. 2018;50:94-103. https://doi.org/10.1016/ j.ijsu.2017.12.029

11. Lee YS, Shin SC, Lim YS, Lee JC, Wang SG, Son SM, et al. Tumor locationdependent skip lateral cervical lymph node metastasis in papillary thyroid cancer. Head Neck. 2014:36(6):887-91. https://doi.org/10.1002/hed.23391.

12. Lei J, Zhong J, Jiang K, Li Z, Gong R, Zhu J. Skip lateral lymph node metastasis leaping over the central neck compartment in papillary thyroid carcinoma. Oncotarget. 2017;8(16):27022-33. https://doi.org/10.18632/ oncotarget.15388.

13. Liu C, Xiao C, Chen J, Li X, Feng Z, Gao Q, et al. Risk factor analysis for predicting cervical lymph node metastasis in papillary thyroid carcinoma: a study of 966 patients. BMC Cancer. 2019;19(1):622. https://doi.org/10.1186/ s12885-019-5835-6.

14. Gambardella C, Tartaglia E, Nunziata A, Izzo G, Siciliano G, Cavallo F, et al. Clinical significance of prophylactic central compartment neck dissection in the treatment of clinically node-negative papillary thyroid cancer patients. World J Surg Oncol. 2016;14(1):247. https://doi.org/10.1186/s12957-016-1003-5.

15. leni A, Barresi V, Cardia R, Licata L, Di Bari F, Benvenga S, et al. The micropapillary/hobnail variant of papillary thyroid carcinoma: a review of series described in the literature compared to a series from one southern Italy pathology institution. Rev Endocr Metab Disord. 2016;17(4):521-7. https://doi.org/10.1007/s11154-016-9398-4

16. Likhterov I, Reis LL, Urken ML. Central compartment management in patients with papillary thyroid cancer presenting with metastatic disease to the lateral neck: Anatomic pathways of lymphatic spread. Head Neck. 2017; 39(5):853-859. oi:https://doi.org/10.1002/hed.24568.

17. Fraser S, Zaidi N, Norlen O, Glover A, Kruijff S, Sywak M, et al. Incidence and risk factors for occult level 3 lymph node metastases in papillary thyroid cancer. Ann Surg Oncol. 2016;23(11):3587-92. https://doi.org/10.1245/ s10434-016-5254-8.

18. Nie X, Tan Z, Ge M, Jiang L, Wang J, Zheng C. Risk factors analyses for lateral lymph node metastases in papillary thyroid carcinomas: a retrospective study of 356 patients. Arch Endocrinol Metab. 2016;60(5):4929. https://doi.org/10.1590/2359-3997000000218.

19. Hu D, Lin H, Zeng X, Wang T, Deng J, Su X. Risk factors for and prediction model of skip metastasis to lateral lymph nodes in papillary thyroid carcinoma. World J Surg. 2020;44(5):1498-505. https://doi.org/10.1007/ s00268-019-05332-0.

20. Zhang F, Oluwo O, Castillo FB, Gangula P, Castillo M, Farag F, et al. Thyroid nodule location on ultrasonography as a predictor of malignancy. Endocr Pract. 2019;25(2):131-7. https://doi.org/10.4158/EP-2018-0361.

21. Jasim S, Baranski TJ, Teefey SA, Middleton WD. Investigating the effect of thyroid nodule location on the risk of thyroid cancer. Thyroid. 2020. 2020; 30(3):401-407. doi:https://doi.org/10.1089/thy.2019.0478

22. Haugen BR, Alexander EK, Bible KC, Doherty G, Mandel SJ, Nikiforov YE, et al. 2015 American Thyroid Association management guidelines for adult patients with thyroid nodules and differentiated thyroid cancer. Thyroid Official Journal of the American Thyroid Association Thyroid. 2016;26(1):1133. https://doi.org/10.1089/thy.2015.0020.

23. Luo Y, Zhao Y, Chen K, Shen J, Shi J, Lu S, et al. Clinical analysis of cervical lymph node metastasis risk factors in patients with papillary thyroid microcarcinoma. J Endocrinol Investig. 2019;42(2):227-36. https://doi.org/10. 1007/s40618-018-0908-y.

24. Kim SY, Kim SM, Chang H, Kim BW, Lee YS, Chang HS, et al. Lateral neck metastases in the ipsilateral and contralateral compartments of papillary thyroid carcinoma located in one lobe. ANZ J Surg. 2019;89(11):E498-e501. https://doi.org/10.1111/ans.15458.

25. Zhao H, Huang T, Li H. Risk factors for skip metastasis and lateral lymph node metastasis of papillary thyroid cancer. Surgery. 2019;166(1):55-60. https://doi.org/10.1016/j.surg.2019.01.025.

26. Kim SK, Park I, Woo JW, Lee JH, Choe JH, Kim JH, et al. Predictive factors for lymph node metastasis in papillary thyroid microcarcinoma. Ann Surg Oncol. 2016;23(9):2866-73. https://doi.org/10.1245/s10434-016-5225-0.

27. Kim JW, Roh JL, Gong G, Cho KJ, Choi SH, Nam SY, et al. Extent of extrathyroidal extension as a significant predictor of nodal metastasis and extranodal extension in patients with papillary thyroid carcinoma. Ann Surg Oncol. 2017;24(2):460-8. https://doi.org/10.1245/s10434-016-5594-4.

28. Zhao W, Chen S, Hou X, Liao Q, Chen G, Zhao Y. Predictive factors of lateral lymph node metastasis in papillary thyroid microcarcinoma. Pathology oncology research : POR. 2019;25(3):1245-51. https://doi.org/10.1007/ s12253-018-0511-8.

29. Attard A, Paladino NC, Lo Monte Al, Falco N, Melfa G, Rotolo G, et al. Skip metastases to lateral cervical lymph nodes in differentiated thyroid cancer: a systematic review. BMC Surg. 2019;18(Suppl 1):112. https://doi.org/10.1186/ s12893-018-0435-y.

30. Sui C, He Q, Du R, Zhang D, Li F, Dionigi G, et al. Lymph node characteristics of $6279 \mathrm{~N} 1$ differentiated thyroid cancer patients. Endocr Connect. 2020. 2020;9(3):201-210. doi:https://doi.org/10.1530/EC-20-0019

31. Sancaktar ME, Saylam G, Ocal B, Uluat A, Bayir O, Cakal E, et al. Possible prediction of patterns of cervical lymph node spread based on primary tumor location in papillary thyroid carcinomas. Turk J Med Sci. 2019;49(1): 217-21. https://doi.org/10.3906/sag-1807-79.

\section{Publisher's Note}

Springer Nature remains neutral with regard to jurisdictional claims in published maps and institutional affiliations.
Ready to submit your research? Choose BMC and benefit from:
- fast, convenient online submission
- thorough peer review by experienced researchers in your field
- rapid publication on acceptance
- support for research data, including large and complex data types
- gold Open Access which fosters wider collaboration and increased citations
- maximum visibility for your research: over $100 \mathrm{M}$ website views per year
At BMC, research is always in progress.
Learn more biomedcentral.com/submissions 